\title{
Mineralization of wood by calcium carbonate insertion for improved flame retardancy
}

\author{
Journal Article \\ Author(s): \\ Merk, Vivian; Chanana, Munish; Gaan, Sabyasachi; Burgert, Ingo \\ Publication date: \\ 2016-09 \\ Permanent link: \\ https://doi.org/10.3929/ethz-b-000119900 \\ Rights / license: \\ In Copyright - Non-Commercial Use Permitted \\ Originally published in: \\ Holzforschung 70(9), https://doi.org/10.1515/hf-2015-0228
}




\section{Vivian Merk, Munish Chanana*, Sabyasachi Gaan and Ingo Burgert* \\ Mineralization of wood by calcium carbonate insertion for improved flame retardancy}

DOI 10.1515/hf-2015-0228

Received October 22, 2015; accepted February 16, 2016; previously published online March 18, 2016

Abstract: Wood can be considered as a highly porous, three-dimensional organic scaffold. It can be mineralized to create hierarchically structured organic-inorganic hybrid materials with novel properties. In the present paper, the precipitation of $\mathrm{CaCO}_{3}$ mineral in Norway spruce and European beech wood has been studied by alternating impregnation with aqueous and alcoholic electrolyte solutions. Microstructural imaging by SEM and confocal Raman microscopy shows the distribution of calcite and vaterite as two $\mathrm{CaCO}_{3}$ polymorphs, which are deposited deep inside the cellular structure of the wood. The confined microenvironment of the wood cell wall seems to favor a formation of vaterite, as visible by XRD and Raman spectroscopy. In view of a practical application, the mineralization of wood opens up ways for sustainable wood-based hybrid materials with a significantly improved fire resistance, as proven via pyrolysis combustion flow calorimetry and cone calorimetry tests. Beyond that, this versatile solute-exchange approach provides an opportunity for the incorporation of a broad range of different mineral phases into wood for novel material property combinations.

Keywords: calcite, calcium carbonate, cone calorimetry, fire retardant, hybrid material, mineral, mineralized wood,

*Corresponding authors: Munish Chanana, ETH Zurich, Institute for Building Materials (IfB), Wood Materials Science, 8093 Zurich, Switzerland; and University of Bayreuth, Physical Chemistry II, 95447 Bayreuth, Germany,

e-mail:munish.chanana@uni-bayreuth.de; and

Ingo Burgert, ETH Zurich, Institute for Building Materials (IfB), Wood Materials Science, 8093 Zurich, Switzerland; and EMPA (Swiss Federal Laboratories for Material Science and Technology), Applied Wood Materials Laboratory, Überlandstrasse 129, 8600 Dübendorf, Switzerland, e-mail: iburgert@ethz.ch

Vivian Merk: ETH Zurich, Institute for Building Materials (IfB), Wood Materials Science, 8093 Zurich, Switzerland; and EMPA (Swiss Federal Laboratories for Material Science and Technology), Applied Wood Materials Laboratory, Überlandstrasse 129, 8600 Dübendorf, Switzerland

Sabyasachi Gaan: EMPA - Swiss Federal Laboratories for Materials Science and Technology, Advanced Fibres, Lerchenfeldstrasse 5, 9014 St. Gallen, Switzerland
PCFC, polymorph, Raman spectroscopy, scanning electron microscopy, vaterite, wood modification

\section{Introduction}

Embedding of minerals into biological tissues is a very common process in nature, e.g. bone, enamel or nacre, and leads to hybrid materials with extraordinary properties due to the synergetic interplay of inorganic and organic components at various levels of hierarchy ranging from the molecular up to the mesoscale level (Mann et al. 1993; Fratzl and Weinkamer 2007; Dunlop et al. 2011). Similar to other organic matrices, the porous biopolymer network of wood is a remarkable platform for depositing inorganic matter in a compartamentalized micro-environment and the literature demonstrates that mineralized wood materials can be obtained with enhanced properties, which have a benefit from the structural integrity of natural wood.

From the plethora of minerals provided by nature, only few minerals have been incorporated via chemical strategies into the wood structure, yet. Examples are silica (Saka and Ueno 1997), titania (Hubert et al. 2010; Mahr et al. 2012) aluminosilicates (Dong et al. 2002), calcium phosphate (Tampieri et al. 2009) and iron oxide (Merk et al. 2014). Calcium carbonate (Merk et al. 2015) was also employed in wood mineralization as it is well known from biomineralization, geology, and industrial applications (Meldrum 2003). However, strategies for $\mathrm{CaCO}_{3}$ mineralization of wood, as reported in the literature, often require a costly technical set-up for supercritical gases (Tsioptsias and Panayiotou 2011), or harmful precursors and reactions, which for example involve elemental calcium, methanol, and hydrogen (Klaithong et al. 2013). Furthermore, the main challenge of a solid wood treatment is to deposit minerals deep inside the wood specimen, avoiding an exclusive precipitation of the mineral at and directly below the wood surface.

In this paper, a simple mineralization strategy of wood will be reported, which involves a subsequental in-situ mineral formation based on a solution-exchange process. By employing alternating solution-exchange cycles wit $\mathrm{CaCl}_{2}$ in ethanol and $\mathrm{NaHCO}_{3}$ in water, a high mass uptake can be achieved, which can be suitable for flame-retardant 
applications, but also for other material properties related to the inorganic character of the created hybrid material.

\section{Materials and methods}

Mineralization: Blocks of Norway spruce (Picea abies (L.) Karst.) and European beech (Fagus sylvatica L.) $\left(1 \times 1 \times 1 \mathrm{~cm}^{3}, 5-15\right.$ sample replicas) sawn from a wood beam were conditioned at $20^{\circ} \mathrm{C} / 65 \%$ RH. Calcium chloride dihydrate (Merck, EMSURE ACS Reag. PhEur, Darmstadt, Germany) and sodium hydrogen carbonate (Merck, EMSURE ACS Reag. PhEur, Darmstadt, Germany) were used without prior purification to prepare solutions in absolute ethanol (Scharlau, ACS, Reag. PhEur, Barcelona, Spain) and in deionized water. After vacuum-assisted impregnation in ethanolic $\mathrm{CaCl}_{2} \cdot 2 \mathrm{H}_{2} \mathrm{O}(\mathrm{c}=1.0 \mathrm{~mol}$ $\mathrm{l}^{-1}$ ) for $10 \mathrm{~h}$, the wood samples were rinsed with ethanol followed by vacuum-assisted impregnation in aqueous $\mathrm{NaHCO}_{3}\left(\mathrm{c}=1.0 \mathrm{~mol} \mathrm{l}^{-1}\right)$ for $14 \mathrm{~h}(\mathrm{pH} \approx 8.2)$ and subsequent rinsing with deionized water. Having completed 1-4 reaction cycles, the mineralized wood samples were equilibrated at $20^{\circ} \mathrm{C} / 65 \% \mathrm{RH}$ to determine the mass gain and to avoid a transformation of the crystalline phases.

Light microscopy: Cross-cut wood specimens were observed under a Leica (Wetzlar, Germany) M165C stereomicroscope (3.2x objective) coupled to a Basler GigE Vision camera (Ahrensburg, Deutschland). Images were recorded with a control plugin (PHASE GmbH) for the software ImageJ 1.47c.

Environmental scanning electron microscopy (ESEM) was carried out on a FEI Quanta 600 (Eindhoven, The Netherlands) in the low-vacuum mode (water vapor, 0.53 Torr) driven by $20 \mathrm{kV}$ acceleration using a SSD detector.

For the Raman measurements $20 \mu \mathrm{m}$ cross-sections were prepared with a rotary microtome (Leica Ultracut, Wetzlar, Germany), placed on a microscopic slide with a few drops of $\mathrm{D}_{2} \mathrm{O}$ and sealed with a cover slip and nail polish to avoid evaporation. All Raman spectra were recorded with a confocal Raman microscope (Renishaw InVia, Wotton-under-Edge, UK) equipped with a Nd-YAG laser $(\lambda=532 \mathrm{~nm})$, a 1800 grooves $\mathrm{mm}^{-1}$ grating and a $100 \times$ oil immersion objective (Nikon, $\mathrm{NA}=1.4$ ), a step width of $300 \mathrm{~nm}$ and an integration time of $0.30 \mathrm{~s}$. The data were processed and scanned for cosmic rays with the software Wire 4.1. Single spectra were plotted with the program OriginPro 8.1 (Northampton, USA). Additionally, for the extraction of hyperspectral data, Vertex Component Analysis (VCA) was performed in the spectral range $900-1700 \mathrm{~cm}^{-1}$ with the MatLab-based software CytoSpec v. 2.00.01 (Peter Lasch, Berlin, Germany) assuming six endmembers.

XRD spectra were collected from chopped mineralized wood (sample volume $\sim 0.25 \mathrm{~cm}^{3}$ ) in triplicate on a Bruker D8 Advance (Karlsruhe, Germany) instrument ranging from $2 \theta=10-80^{\circ}$ equipped with a copper source $[\lambda(\mathrm{CuK} \alpha 1)=0.154 \mathrm{~nm}, 40 \mathrm{kV}$ voltage, $40 \mathrm{~mA}$ current] and a rotating flat disk sample holder using a scan speed of $0.15^{\circ} \mathrm{min}^{-1}$.

Pyrolysis combustion flow calorimetry (PCFC): The heat of combustion of wood $/ \mathrm{CaCO}_{3}$ composites and reference wood (conditioned at $20^{\circ} \mathrm{C} / 65 \% \mathrm{RH}$ ) was determined by PCFC (Fire Testing Technology Instrument, East Grinstead, UK) according to (Lyon and Walters 2004) with a pyrolysis temperature of $85-750^{\circ} \mathrm{C}$ and a $80: 20 \mathrm{~N}_{2} / \mathrm{O}_{2}$ gas mixture and operated at a heating rate of $\beta=1 \mathrm{Ks}^{-1}$ and a combustion temperature of $900^{\circ} \mathrm{C}$. The PCFC measurements were replicated at least five times per sample with a weight of ca. $5 \mathrm{mg}$. The HRR curves were baseline-corrected and fitted with multiple Gauss curves using the software OriginPro 8.1. Herein, the resulting peak sum (the total heat release) displayed residual values close to 1 . The maximum heat release divided by the constant heating rate $\beta=1 \mathrm{Ks}^{-1}$ gives the heat release capacity. Samples were weighed before $\left(\mathrm{m}_{0}\right)$ and after $\left(\mathrm{m}_{1}\right)$ micro-calorimetry testing. The char yield is calculated from $\mu=\left(\mathrm{m}_{0}\right.$ $\left.\mathrm{m}_{1}\right) \cdot 100 \% / \mathrm{m}_{0}$.

In cone calorimetry testing (Fire Testing Technology Instrument, East Grinstead, UK), wood samples (five samples per variation) were exposed to a constant uniform irradiation of $50 \mathrm{~kW} \mathrm{~m}^{-2}\left(\mathrm{~T} \approx 750^{\circ} \mathrm{C}\right)$ in the horizontal position according to the ISO 5660-1 norm. The heat release rate (HRR) was calculated based on the oxygen consumption. Bulk densities of the samples were determined at $20^{\circ} \mathrm{C} / 65 \% \mathrm{RH}$ prior to chemical modification. After a vacuum-drying step at $65^{\circ} \mathrm{C}$, the samples $\left(L \approx 100 \times R \approx 100, T \approx 10 \mathrm{~mm}^{3}\right)$ were treated in four mineralization cycles, where the relative mass gain were $17 \pm 2 \%$ (spruce) and $18 \pm 2 \%$ (beech). Then the samples were washed with water for $30 \mathrm{~min}$, dried in a vacuum kiln, and conditioned to $20^{\circ} \mathrm{C} / 65 \% \mathrm{RH}$. The samples were mounted onto the loading cell in an aluminum boot and a standard metal frame.

FT-IR spectra of char residues obtained from cone calorimetry testing were collected with a Tensor 27 spectrometer (Bruker, Fällanden, Switzerland) equipped with a Pike ATR cell in a spectral range of 4000-350 $\mathrm{cm}^{-1}$ with $4 \mathrm{~cm}^{-1}$ spectral resolution and averaged over 100 scans. The spectra were recorded with the program OPUS and plotted with OriginPro 8.1.

\section{Results and discussions}

Calcium carbonate can be inserted deep into the wood structure by employing alternating solution-exchange cycles of highly concentrated electrolytes (Figure 1a) with $\mathrm{CaCl}_{2}$ in ethanol and $\mathrm{NaHCO}_{3}$ in water. The electrolytes contain ionic precursors that react instantaneously to anhydrous $\mathrm{CaCO}_{3}$ polymorphs. Wood is incubated successively with salt solutions, thus $\mathrm{CaCO}_{3}$ mineral formation is primarily governed by the high supersaturation.

A main advantage of a successive impregnation is the versatility regarding the mineral composition and the high degree of mineralization, which is easily tunable by the number of reaction cycles (Figure 1b,c). After four cycles, high relative mass gains (MG) of over 35\% in spruce and $25 \%$ in beech (Figure $1 \mathrm{~b}$ ) were achieved, but it should be noted that besides $\mathrm{CaCO}_{3}$ the samples most probably contain side products, such as $\mathrm{NaCl}$, or unreacted salts in smaller amounts. For the small samples, the absolute MG (Figure 1c) is similar for spruce and beech, though they have different bulk density and cellular structure, and this reflects the versatility of this approach. Despite of the high total MGs in the samples, there is a MG gradient due to the fast reaction between ionic precursors, which is manifested by a higher mineral accumulation near the 


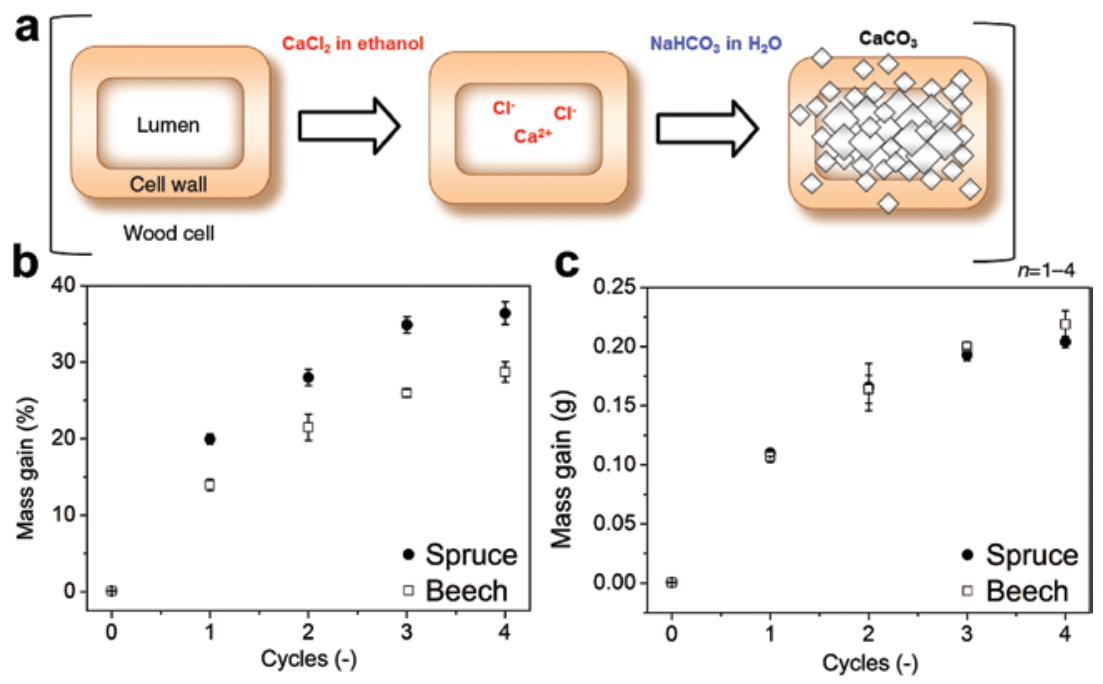

Figure 1: (a) Scheme of mineralization via liquid exchange of alternating impregnations with $\mathrm{CaCl}_{2}$ in ethanol and $\mathrm{NaHCO}_{3}$ in $\mathrm{H}_{2} \mathrm{O}$. Averaged relative (b) and absolute mass gain (c) of cubic spruce and beech specimens ( $1 \mathrm{~cm}^{3}$ volume) after cycled solution-exchange process with $1 \mathrm{M}$ $\mathrm{CaCl}_{2} \cdot 2 \mathrm{H}_{2} \mathrm{O}$ in ethanol and $1 \mathrm{M} \mathrm{NaHCO}_{3}$ in $\mathrm{H}_{2} \mathrm{O}$.

surface readily visible as whitish $\mathrm{CaCO}_{3}$ precipitate from the outside.

Both the mineral composition and the solvents can be varied. The initial infiltration is slightly better, when $\mathrm{CaCl}_{2}$ is supplied as alcoholic instead of water solution (data not shown), because this approach allows trapping the $\mathrm{NaHCO}_{3}$ precursor salt in the wood structure by taking advantage of its low solubility in ethanol. The mineral precipitation occurs spontaneously and quantitatively due to its poor solubility in both solvents. After four solution-exchange cycles, however, the mineral uptake reaches the saturation level irrespective of the employed solvent. Hence, a purely water-based mineralization can also be envisaged from the environmental and economic point of view.

Light microscopy at low magnification shows large amounts of mineral precipitates in large cavities, namely spruce earlywood (EW) tracheids and beech vessels (Figure 2a,d). Closer observation with SEM reveals the
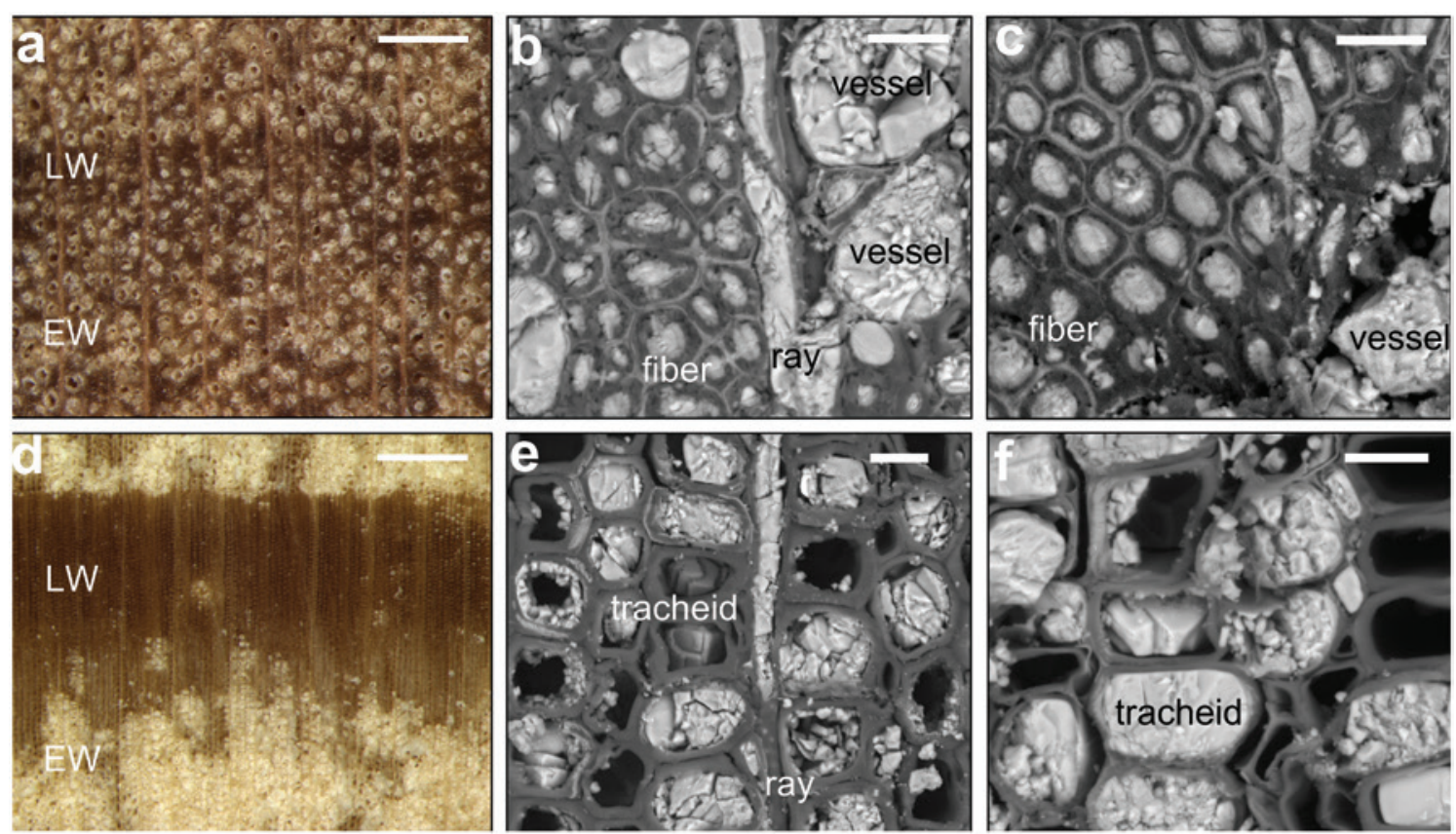

Figure 2: Light microscope and SEM images of $\mathrm{CaCO}_{3} /$ wood composites obtained in the backscattered electron mode, beech (a-c) and spruce (d-f) cross sections. The scale bar corresponds to $500 \mu \mathrm{m}(\mathrm{a}, \mathrm{d})$ and $20 \mu \mathrm{m}(\mathrm{b}, \mathrm{c}, \mathrm{e}, \mathrm{f})$. 
prevailing deposition of polycrystalline $\mathrm{CaCO}_{3}$ in the lumina of beech vessels and fibers (Figure $2 b, c$ ) or spruce tracheids (Figure 2e,f). The deposition pattern of $\mathrm{CaCO}_{3}$ mineral seems to coincide with the microporous structure that facilitates fluid transport in wood.

$\mathrm{CaCO}_{3}$ precipitates in rays (Figure 2b,e) or in interconnecting pit channels of neighboring beech fiber cells (Figure 2a-d) indicate, in addition to that in micropores of the axial tissues, that an ion transport occurs perpendicular to the wood fiber direction. Furthermore, in the case of beech, high amounts of electron-lucent material are also visible in the cell corners and the compound middle lamellae (CML) of the fibers (Figure 2b,c). This might be either explained by the adsorption of calcium cations to negatively charged and metal-complexing surfaces within the cell wall regions rich in pectin and lignin (Grant et al. 1973; Jarvis 1984; Cooper 1998; Petric et al. 2000; Caffall and Mohnen 2009) or by an increased ion transport to the CML from the lumen across the pit membranes (Cooper 1998; Petric et al. 2000; Gindl et al. 2003).

The mineral distribution in the wood structure differs substantially from the mineralization in a one-pot method (Merk et al. 2015). In the quoted work, a neutral molecule (dimethyl carbonate) served as carbonate source and was hydrolyzed to $\mathrm{CO}_{2}$ upon adding excess base. It was observed that $\mathrm{CaCO}_{3}$ was predominantly formed in the cell walls and the lumina were hardly filled. From the present work, it can be assumed that capillary effects of pores in the cell walls are involved in controlling the deposition pattern.

Judging from the mineral morphology, in the first instance, the $\mathrm{CaCO}_{3}$ precipitates seem to be constituted mainly of calcite. However, a closer look reveals that the resultant mineralization product is a mixture of calcite and vaterite according to X-ray powder diffraction (Figure 3) and Raman spectroscopy (Figure 4) both in spruce or beech. Under the present reaction conditions $(\mathrm{pH} \approx 8.2$ ), the initially formed metastable vaterite is expected to gradually transform into calcite (Spanos and Koutsoukos 1998; Sheng Han et al. 2006; Bao et al. 2011). Vaterite, however, is remarkably stable in dry wood samples over several months, which might be explained by the effect of confined spaces in the wood microstructure.

Figure 4 shows confocal Raman microscopic mappings of $\mathrm{CaCO}_{3} /$ wood composites. Vertex component analysis (VCA) is a powerful multivariate method which allows for discerning the polymeric wood cell wall components and different $\mathrm{CaCO}_{3}$ mineral polymorphs, as described elsewhere (Gierlinger 2014; Keplinger et al. 2015; Merk et al. 2015). The respective endmember mappings show the distribution of carbohydrates in the S2 cell

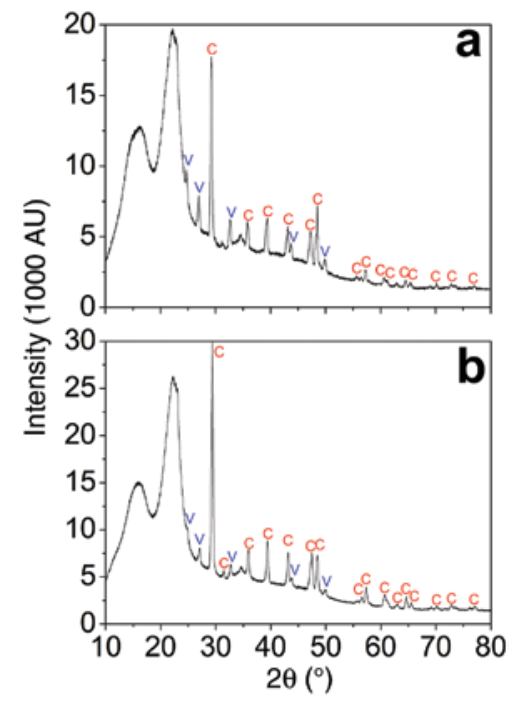

Figure 3: X-ray powder diffraction of typical $\mathrm{CaCO}_{3} /$ wood composite of spruce (a) and beech (b) with characteristic X-ray line pattern of calcite (C) and vaterite (V) according to literature (Kralj et al. 1990; King et al. 1993).

wall layer (Figure 4a,e,i,m) and different $\mathrm{CaCO}_{3}$ phases (Figure 4b,c,f,g,j,k,n,o). On the basis of Raman signals, the calcitic and vateric form of $\mathrm{CaCO}_{3}$ can be easily distinguished. Calcite gives rise to an intense $v_{1}$ vibration band at $1085 \mathrm{~cm}^{-1}$ (Rutt and Nicola 1974), whereas the $v_{1}$ mode of vaterite splits into a doublet at $1089 \mathrm{~cm}^{-1}$ and $1074 \mathrm{~cm}^{-1}$ (Behrens et al. 1995; Kontoyannis and Vagenas 2000). A smaller portion of $\mathrm{CaCO}_{3}$ is localized within the cell walls and along the CML (Figure 4b,f,j,n). In the nanoporous wood cell walls, the formation of the more soluble polymorph vaterite seems to be favored over calcite. This could be due to the high local supersaturation of ions in the confined cellular pores (Falini et al. 1996), which coincides with a lower $\mathrm{pH}$ drop. In various natural organic/ inorganic hybrid materials, oversaturation in confined space governs the formation of the less stable mineral polymorph (Falini et al. 1996; Falini et al. 2000; Falini et al. 2002; Rodriguez-Navarro et al. 2007; Meldrum and Cölfen 2008; Cantaert et al. 2013; Kirboga and Oner 2013). For instance, sustained supersaturation is decisive for the formation of vaterite in solution and for inhibiting its transformation into calcite (Spanos and Koutsoukos 1998; Sheng Han et al. 2006).

Apart from pore confinement effects, negatively charged groups on the surface might also mediate crystallization (Mann et al. 1991). The high density of calcium-complexating surface sites, especially lignin and pectin in the CML (Grant et al. 1973; Jarvis 1984; Caffall and Mohnen 2009) likely promotes the formation of $\mathrm{CaCO}_{3}$ (Figure 4b,f,j,n). In primary cell walls, pectin 

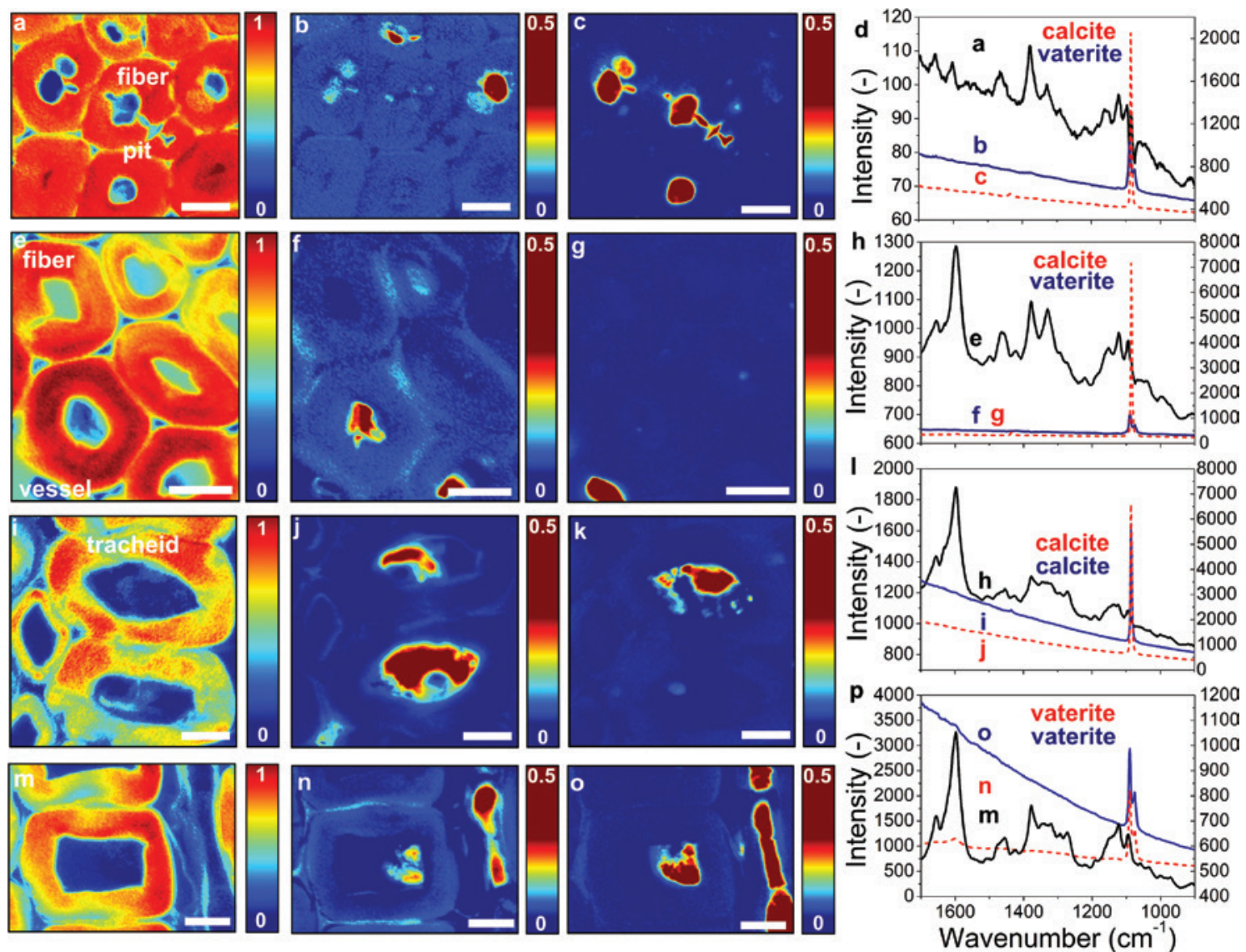

Figure 4: Raman mapping of $\mathrm{CaCO}_{3}$ precipitates in beech and spruce $(\mathrm{h}-0)$. Vertex component analysis showing spatial distribution of cell wall carbohydrates (a, e, h, l), $\mathrm{CaCO}_{3}$ polymorphs vaterite (b, f, i, $\mathrm{m}, \mathrm{n}$ ) and calcite (c, g, j) and corresponding endmember spectra (d, h, k, h). The scale-bar corresponds to $10 \mu \mathrm{m}$.

(homogalacturonan) forms complex networks ionically cross-linked by calcium (Cosgrove 2005). In solution, (esterified) pectin slightly favors the formation of more soluble $\mathrm{CaCO}_{3}$ phases or liquid precursor phases by destabilizing prenucleation clusters and inhibiting mineral nucleation (Rao et al. 2014). Furthermore, a transformation of the thermodynamically metastable vaterite to the stable calcite polymorph might occur more easily in larger cavities in a range of several tens of $\mu \mathrm{m}$ (beech vessels, spruce EW tracheids) due to better fluid convection and mixing. In aqueous media, vaterite transforms into calcite by dissolution and crystallization from solution (Kralj et al. 1994). This seems to be less likely inside the compartmentalized nano-environment of the wood cell walls.

As previously demonstrated, a high content of incombustible $\mathrm{CaCO}_{3}$ mineral renders wood less flammable (Merk et al. 2015). To evaluate the flammability of these $\mathrm{CaCO}_{3} /$ wood composites on the micro- and the benchscale, the pyrolysis combustion flow calorimetry (PCFC) and cone calorimetry were applied. In micro-calorimetry, samples are pyrolized in an inert $\mathrm{N}_{2}$ gas stream according to a temperature ramp followed by high temperature oxidation of the gaseous combustion products in a gas mixture 80/20 $\left(\mathrm{N}_{2} / \mathrm{O}_{2}\right)$ (Lyon and Walters 2004; Sonnier et al. 2011). In Figure 5a, the heat release rate (HRR) of mineralized (colored curves) and untreated spruce (black curve) is plotted against the temperature. In good accordance with calorific values reported in the literature (Shafizadeh 1982; White 1987), the greater lignin content in softwoods gives rise to higher total heat release (THR), heat release capacity (HRC), and char residue values than in hardwood references. In $\mathrm{CaCO}_{3} /$ wood composites, the THR (Figure 5b), HRC (Figure 5c) and temperature of highest mass loss $\left(\mathrm{T}_{\max }\right)$ are significantly lowered compared to the natural wood. Additionally, the THC and HRC remain more or less similar for various treatment cycles. A slightly more pronounced THR and HRC decrease has been found for spruce, presumably due to its higher relative mineral content. In the PCFC tests, the char yield of mineralized wood is approximately doubled as compared to unmodified wood (Figure 5d). A small amount of $\mathrm{CaCO}_{3}$ seems to be disproportionally effective in increasing the char yield 


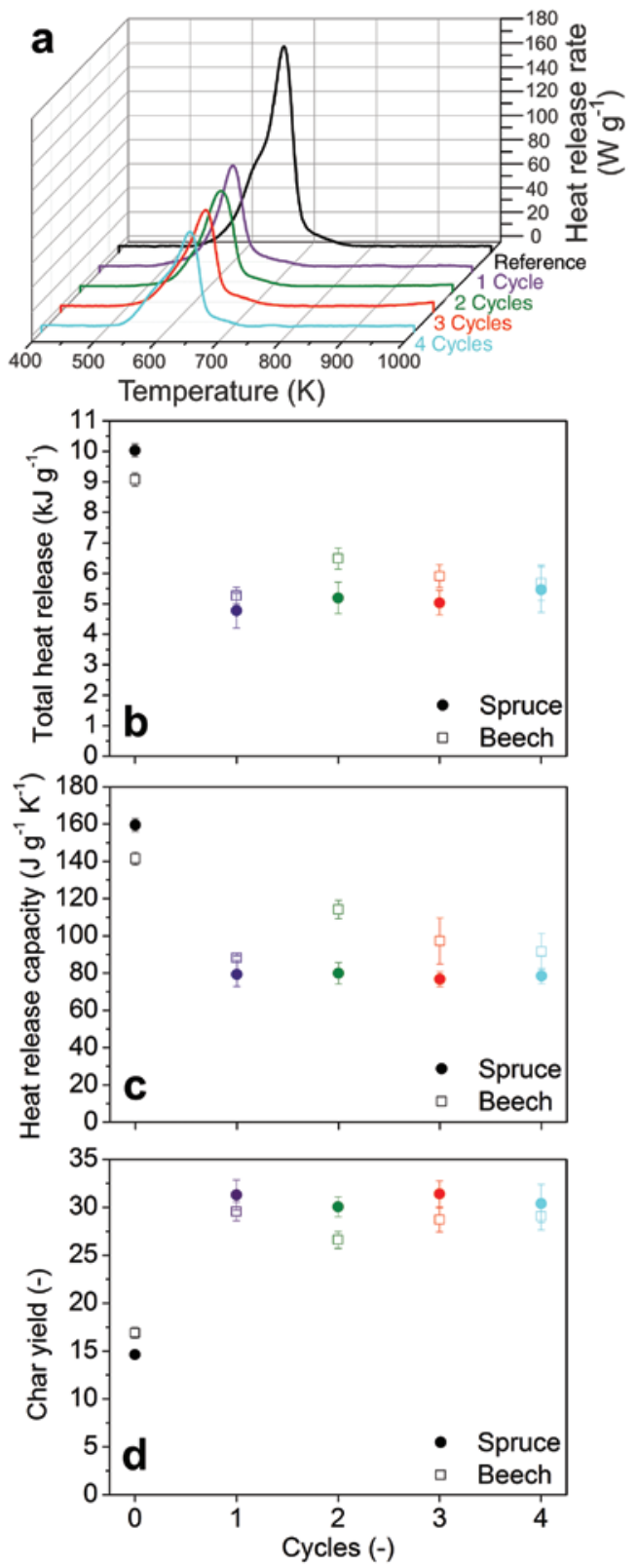

Figure 5: Pyrolysis combustion flow calorimetry.

(a) Heat release curves for natural (black line) and mineralized spruce (colored lines) averaged over five measurements. Total heat release (b), heat release capacity (c) and char yield are plotted as a function of the mineralization cycle for spruce and beech composites.

and the fire retardance of wood composites. These results are highly consistent with our previously published data (Merk et al. 2015), and it can be concluded that similar or even identical thermal decomposition mechanism are valid, and hence, the fire retarding performances are also similar.

Cone calorimetry tests of mineralized and pristine wood samples have been performed to simulate the combustion behavior in a developing fire (Schartel et al. 2005;
Schartel and Hull 2007). In comparison to PCFC, physical fire-retardant mechanisms are more amenable to be studied in cone calorimetry (Sonnier et al. 2011). In this flammability test, wood samples are subjected to a constant heat flux of $50 \mathrm{~kW} \mathrm{~m}{ }^{-2}$ from a conical radiant panel under well-ventilated conditions. As soon as sufficient pyrolysis gasses have evolved from the wood specimen, piloted ignition starts. In our studies, the observed time to ignition (Table 1) is hardly affected by the mineralization treatment.

Bimodal heat release profiles of beech and spruce timber are displayed in Figure 6a,b. Peaks of heat release rate (PHRR) correspond to flaming combustion, which is a cause of rapid fire spread in the environment. The initial PHRR (visualized in Figure $6 c, t=40 s$ ) originates from the oxidation of volatile pyrolysis products (Lowden and Hull 2013). As combustion proceeds, lowering of HRR indicates the formation of an insulating layer (Schartel et al. 2005; Batiot et al. 2014). When the protective char structure breaks up, the HRR undergoes a second maximum followed by gradual glowing and smoldering combustion (Lowden and Hull 2013). The thermo-oxidative decomposition of the condensed phase mainly occurs through cracks on the char surface as a result of the built-up gas pressure in deeper layers (Batiot et al. 2014). Only in native wood, major deformation was observed during the afterglow phase due to residual stress (Figure $6 c, t=450 \mathrm{~s}$ ). In mineralized wood, both peak HRR are substantially decreased and shifted to longer exposure times (Table 1), which indicates a lower fire growth rate and enhanced char stabilization. In essence, the PHRR values are reduced to a similar extent as in other fire-retardant systems reported in the literature (Simkovic et al. 2005; Simkovic et al. 2007; Hagen et al. 2009; Grześkowiak 2012; Mahr et al. 2012). As the mass loss values of unmodified and mineralized woods are comparable (Table 1), it can be assumed that the improved fire retardance of mineralized wood results from a combination of both physical and chemical effects. Incombustible minerals embedded into wood tissues most likely dilute the amount of combustible material and constitute a barrier for heat and mass transport during the pyrolysis. As depicted in Figure 7a, native wood yields brownish-black, highly disintegrated residues, whereas compact residues with partially intact cellular ultrastructure are seen in mineralized samples. Herein, the residue yield clearly exceeds the amount of incorporated mineral. Together with the lowered $\mathrm{T}_{\max }$ recorded in PCFC, this indicates a base-catalyzed pyrolysis of cellulose (Shafizadeh 1982; Di Blasi et al. 2009; Merk et al. 2015).

Differences in the chemical composition of the heattreated woods studied were observed by FTIR spectroscopy (Figure 7b). In reference wood, the absence of a $\mathrm{O}-\mathrm{H}$ 
Table 1: Cone calorimetry data obtained at $50 \mathrm{~kW} \mathrm{~m}^{-2}$ averaged over five samples per variation.

\begin{tabular}{|c|c|c|c|c|}
\hline Parameters & Untreated beech & Mineralized beech & Untreated spruce & Mineralized spruce \\
\hline $\mathrm{t}_{\text {Ignition }}(\mathrm{s})$ & $28 \pm 4$ & $30 \pm 5$ & $18 \pm 3$ & $18 \pm 1$ \\
\hline Initial mass (g) & $61 \pm 2$ & $76 \pm 1$ & $42 \pm 2$ & $49 \pm 2$ \\
\hline Total mass loss (\%) & $60 \pm 1$ & $59 \pm 2$ & $41 \pm 2$ & $39 \pm 2$ \\
\hline THR (MJ m-2) & $129 \pm 23$ & $84 \pm 20$ & $81 \pm 17$ & $63 \pm 18$ \\
\hline $\mathrm{t}_{\text {1. PHRR }}(\mathrm{s})$ & $60 \pm 20$ & $49 \pm 7$ & $36 \pm 4$ & $30 \pm 6$ \\
\hline 1. $\operatorname{PHRR}\left(\mathrm{kW} \mathrm{m}^{-2}\right)$ & $190 \pm 13$ & $96 \pm 10$ & $173 \pm 16$ & $105 \pm 18$ \\
\hline $\mathrm{t}_{2 . \text { PHRR }}(\mathrm{s})$ & $307 \pm 15$ & $464 \pm 10$ & $354 \pm 11$ & $420 \pm 13$ \\
\hline 2. PHRR $\left(\mathrm{kW} \mathrm{m}^{-2}\right)$ & $402 \pm 61$ & $152 \pm 18$ & $151 \pm 5$ & $113 \pm 11$ \\
\hline
\end{tabular}

THR, Total heat release; PHRR, peak heat release rate.
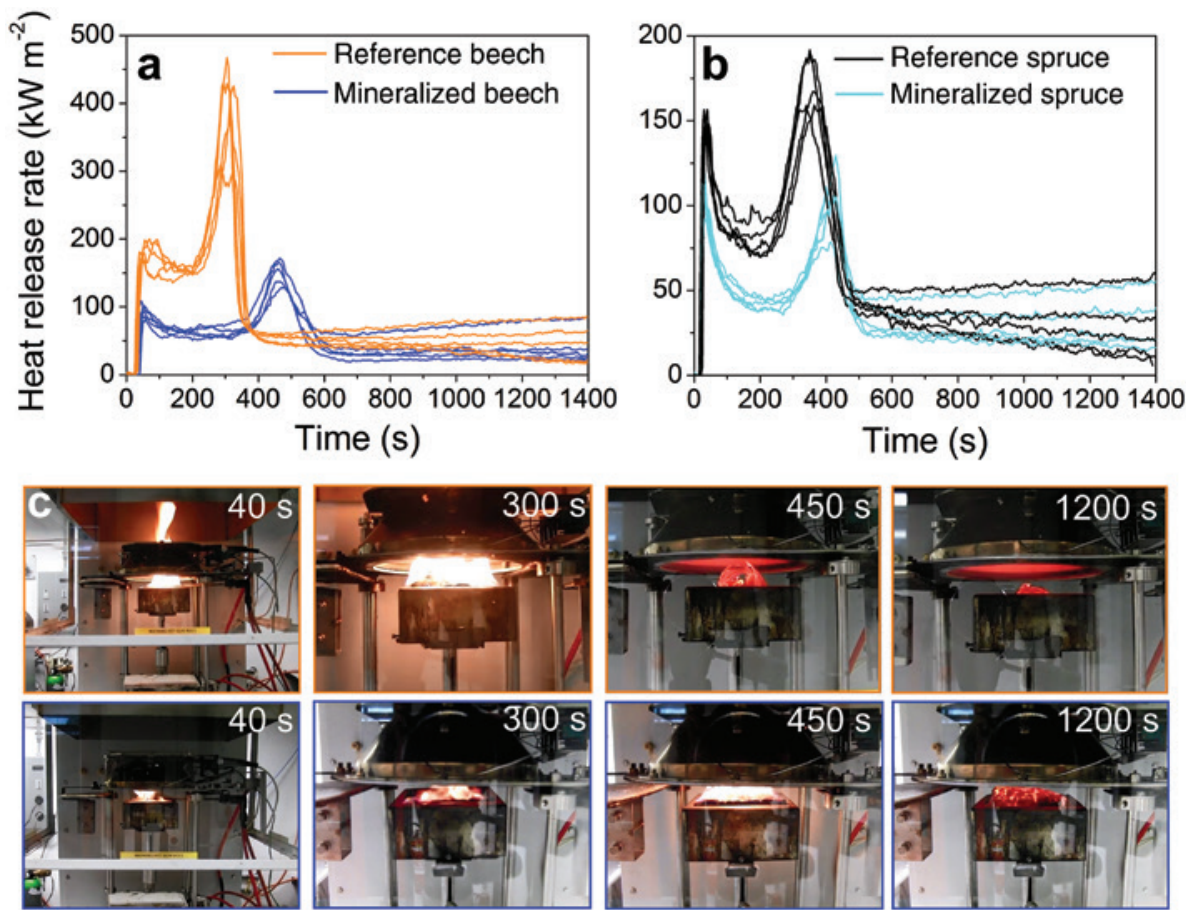

Figure 6: Cone calorimetry data. Heat release profiles of unmodified (orange) and mineralized beech (blue) (a), pristine (black) and modified spruce (turquoise) (b). (c) Photos of cone calorimeter measurements of beech. Incandescent flaming is observed in reference beech (orange frame). The PHRR in untreated beech is shifted from $300 \mathrm{~s}$ to $450 \mathrm{~s}$ in mineralized beech (blue frame).

stretching vibration band $\left(\sim 3300 \mathrm{~cm}^{-1}\right)$ (Nishimiya et al. 1998) indicates a complete dehydration to carbonaceous char, which does not occur in mineralized wood. Infrared spectra of mineralized wood residues display modes originating from untransformed calcite (1796, 872, 847 and $712 \mathrm{~cm}^{-1}$ ) (Xyla and Koutsoukos 1989) and remnant aromatic constituents (1400 and $1630 \mathrm{~cm}^{-1}$ ) (Nishimiya et al. 1998).

Apart from the heat release rate, other reaction-to-fire characteristics, e.g. the generation of toxic gasses or soot, are relevant for evaluating the fire hazard. Upon endothermic decomposition (Satterfield and Feakes 1959), $\mathrm{CaCO}_{3}$ releases carbon dioxide which potentially dilutes and cools flammable combustion products. In correlation with a lowered HRR, smoke production is suppressed in $\mathrm{CaCO}_{3} /$ wood composites (Figure 7c,d).

The various sample preparation procedures and test conditions have to be taken into account (Sonnier et al. 2011), when comparing HRC (Figure 5c) and PHRR results (Table 1) obtained by PCFC or cone calorimetry. For instance, PCFC requires only milligram quantities, whereas cone calorimetry samples have a uniform volume of $\sim 10 \times 10 \times 1 \mathrm{~cm}^{3}$. Despite a lower relative mass uptake $(17 \pm 2 \%$ in spruce, $18 \pm 2 \%$ in beech) in cone calorimetry samples, a substantially improved fire retardance was achieved compared to reference wood. HRC values are reduced to ca. 65\% (beech) and 49\% (spruce) after four 
a

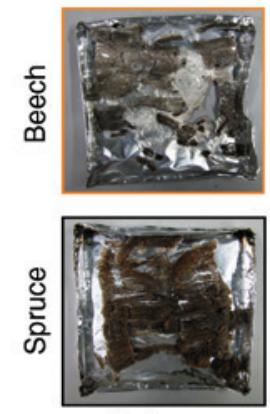

Reference
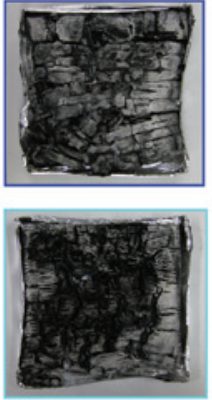

Mineralized
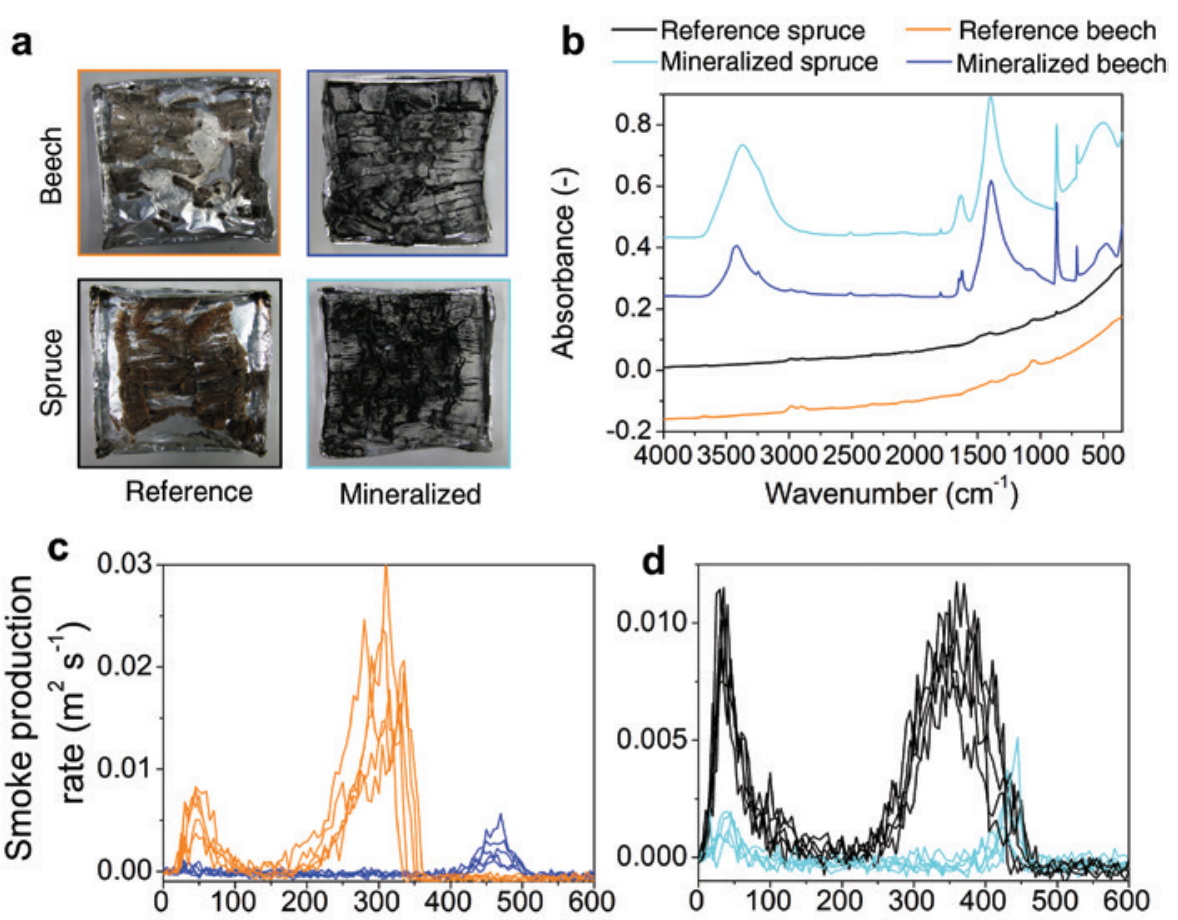

Time (s)

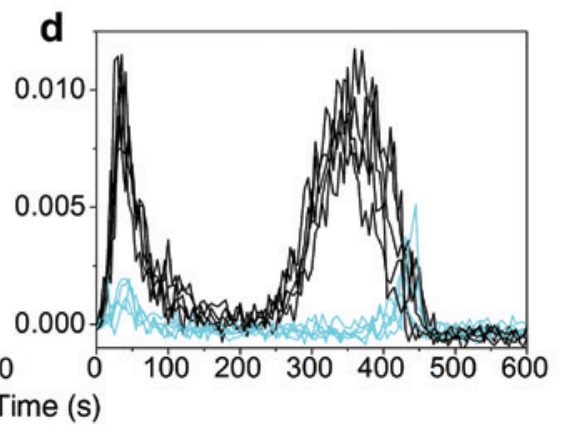

Figure 7: (a) Photographs of char residues of unmodified (orange) and mineralized beech (blue) (a), pristine (black) and modified spruce (turquoise) after combustion. (b) FTIR spectra of char residues. Dynamic smoke production rate of beech (c) and spruce (d) as a function of time.

mineralization cycles, while PHRR values are decreased to $38 \%$ and $61 \%$, respectively. The higher bulk density of the beech samples $\left(\rho=688 \pm 17 \mathrm{~kg} \mathrm{~m}^{-3}\right)$ compared to the spruce samples $\left(\rho=458 \pm 19 \mathrm{~kg} \mathrm{~m}^{-3}\right)$ explains the higher THR and PHRR values of beech in cone calorimetry tests. When higher amounts of fuel are available, embedded fire-proof minerals might be more effective in slowing down the decomposition by limiting the oxygen and volatile supply. Barrier effects do not become apparent in non-flaming PCFC testing, as pyrolysis processes in the solid state are separated from the vapor phase (Lyon and Walters 2004).

\section{Conclusions and outlook}

In focus was the in-situ formation of $\mathrm{CaCO}_{3}$ mineral by subsequent impregnation of wood with aqueous $\mathrm{NaHCO}_{3}$ and alcoholic $\mathrm{CaCl}_{2}$ electrolytes. The SEM, XRD, and Raman microscopic studies showed the deposition of high amounts of polycrystalline calcite and vaterite inside the wood lumina and to a lesser extent in adjacent cell walls. By performing micro-calorimetry and cone-calorimetry tests, a significantly improved fire resistance of $\mathrm{CaCO}_{3} /$ wood composites was demonstrated. Hence, the embedding of incombustible $\mathrm{CaCO}_{3}$ into the wood can be considered as an eco-friendly fire-retardant treatment. The probability is high that the presented approach can be upscaled to an industrial level.

The solute-exchange approach offers a high degree of versatility towards the mineral composition, mineral phase, and amounts of mineral in the wood structure as well as the choice of solvents. Various mineral compositions comprising different cations (earth alkali, light and heavy metals) and anions (carbonates, phosphates, sulfates, etc.) or mixtures thereof could be inserted into the wood structure, in analogy to the impregnation protocol as depicted for calcium carbonate formation in this study. From a fundamental research perspective, the mineralization of woody tissues sheds light on basic processes such as ion transport, crystal nucleation and growth. Further control over the mineral distribution, phase and morphology and their impact on the mechanical performance of wood-based hybrid materials will be subject of future studies.

Acknowledgments: We acknowledge the Bundesamt für Umwelt (BAFU) and Lignum, Switzerland for the financial support of the Wood Materials Science group and Milijana Jovic, Advanced Fibres Lab, EMPA, for help in cone calorimetry measurements and the "Materials for Renewable Energy”, EMPA for technical support in XRD measurements. Munish Chanana thanks Prof. Andreas Fery for his support. 


\section{References}

Bao, S.P., Chen, X.Y., Li, Z., Yang, B.J., Wu, Y.C. (2011) Effects of solvent and additive on controllable mineralization of $\mathrm{MCO}_{3}$ $(\mathrm{M}=\mathrm{Ca}, \mathrm{Ba}, \mathrm{Sr})$ crystals and their applications as red phosphors doped with $\mathrm{Eu}^{3+}$ ions. CrystEngComm. 13:2511-2520.

Batiot, B., Luche, J., Rogaume, T. (2014) Thermal and chemical analysis of flammability and combustibility of fir wood in cone calorimeter coupled to FTIR apparatus. Fire Mater. 38:418-431.

Behrens, G., Kuhn, L.T., Ubic, R., Heuer, A.H. (1995) Raman spectra of vateritic calcium carbonate. Spectrosc. Lett. 28:983-995.

Caffall, K.H., Mohnen, D. (2009) The structure, function, and biosynthesis of plant cell wall pectic polysaccharides. Carbohydr. Res. 344:1879-1900.

Cantaert, B., Beniash, E., Meldrum, F.C. (2013) Nanoscale confinement controls the crystallization of calcium phosphate: relevance to bone formation. Chemistry 19:14918-14924.

Cooper, P.A. (1998) Diffusion of copper in wood cell walls following vacuum treatment. Wood Fiber Sci. 30:382-395.

Cosgrove, D.J. (2005) Growth of the plant cell wall. Nat. Rev. Mol. Cell. Biol. 6:850-861.

Di Blasi, C., Galgano, A., Branca, C. (2009) Influences of the chemical state of alkaline compounds and the nature of alkali metal on wood pyrolysis. Ind. Eng. Chem. Res. 48:3359-3369.

Dong, A., Wang, Y., Tang, Y., Ren, N., Zhang, Y., Yue, Y., Gao, Z. (2002) Zeolitic tissue through wood cell templating. Adv. Mater. 14:926-929.

Dunlop, J.W.C., Weinkamer, R., Fratzl, P. (2011) Artful interfaces within biological materials. Mater. Today 14:70-78.

Falini, G., Albeck, S., Weiner, S., Addadi, L. (1996) Control of aragonite or calcite polymorphism by mollusk shell macromolecules. Science 271:67-69.

Falini, G., Fermani, S., Gazzano, M., Ripamonti, A. (2000) Polymorphism and architectural crystal assembly of calcium carbonate in biologically inspired polymeric matrices. J. Chem. Soc., Dalton Trans. 3983-3987.

Falini, G., Fermani, S., Ripamonti, A. (2002) Crystallization of calcium carbonate salts into beta-chitin scaffold. J. Inorg. Biochem. 91:475-480.

Fratzl, P., Weinkamer, R. (2007) Nature's hierarchical materials. Prog. Mater Sci. 52:1263-1334.

Gierlinger, N. (2014) Revealing changes in molecular composition of plant cell walls on the micron-level by Raman mapping and vertex component analysis (VCA). Front. Plant Sci. 5:306.

Gindl, W., Zargar-Yaghubi, F., Wimmer, R. (2003) Impregnation of softwood cell walls with melamine-formaldehyde resin. Bioresour. Technol. 87:325-330.

Grant, G.T., Morris, E.R., Rees, D.A., Smith, P.J.C., Thom, D. (1973) Biological interactions between polysaccharides and divalent cations: the egg-box model. FEBS Letters 32:195-198.

Grześkowiak, W.t. (2012) Evaluation of the effectiveness of the fire retardant mixture containing potassium carbonate using a cone calorimeter. Fire Mater. 36:75-83.

Hagen, M., Hereid, J., Delichatsios, M.A., Zhang, J., Bakirtzis, D. (2009) Flammability assessment of fire-retarded Nordic Spruce wood using thermogravimetric analyses and cone calorimetry. Fire Saf. J. 44:1053-1066.

Hubert, T., Unger, B., Bucker, M. (2010) Sol-gel derived TiO2 wood composites. J. Sol-Gel Sci. Technol. 53:384-389.
Jarvis, M.C. (1984) Structure and properties of pectin gels in plantcell walls. Plant Cell Environ. 7:153-164.

Keplinger, T., Cabane, E., Chanana, M., Hass, P., Merk, V., Gierlinger, N., Burgert, I. (2015) A versatile strategy for grafting polymers to wood cell walls. Acta Biomater. 11:256-263.

King, M., McClune, W.F., Andrews, L.C., Holomany, M.A., Kahmer, T.M., Lawyer, B., Zwell, L., Post, B., Weissmann, S., McMurdie, H.F., Bayliss, P., Mrose, M.E. (1993) Mineral powder diffraction file, Databook, Sets 1-42. JCPDS - International Centre for Diffraction Data, Park Lane, USA. Databook.

Kirboga, S., Oner, M. (2013) Investigation of calcium carbonate precipitation in the presence of carboxymethyl inulin. CrystEngComm. 15:3678-3686.

Klaithong, S., Van Opdenbosch, D., Zollfrank, C., Plank, J. (2013) Preparation of $\mathrm{CaCO}_{3}$ and $\mathrm{CaO}$ replicas retaining the hierarchical structure of spruce wood. Z. Naturforsch. B. 68:533-538.

Kontoyannis, C.G., Vagenas, N.V. (2000) Calcium carbonate phase analysis using XRD and FT-Raman spectroscopy. Analyst 125:251-255.

Kralj, D., Brecevic, L., Nielsen, A.E. (1990) Vaterite growth and dissolution in aqueous solution I. Kinetics of crystal growth. J. Cryst. Growth. 104:793-800.

Kralj, D., Brečević, L., Nielsen, A.E. (1994) Vaterite growth and dissolution in aqueous solution II. Kinetics of dissolution. J. Cryst. Growth 143:269-276.

Lowden, L., Hull, T. (2013) Flammability behaviour of wood and a review of the methods for its reduction. Fire Sci. Rev. 2:4

Lyon, R.E., Walters, R.N. (2004) Pyrolysis combustion flow calorimetry. J. Anal. Appl. Pyrolysis. 71:27-46.

Mahr, M.S., Hubert, T., Sabel, M., Schartel, B., Bahr, H., Militz, H. (2012) Fire retardancy of sol-gel derived titania wood-inorganic composites. J. Mater. Sci. 47:6849-6861.

Mann, S., Archibald, D.D., Didymus, J.M., Douglas, T., Heywood, B.R., Meldrum, F.C., Reeves, N.J. (1993) Crystallization at inorganic-organic interfaces: biominerals and biomimetic synthesis. Science 261:1286-1292.

Mann, S., Heywood, B.R., Rajam, S., Walker, J.B.A. (1991) Structural and stereochemical relationships between Langmuir monolayers and calcium-carbonate nucleation. J. Phys. D-Appl. Phys. 24:154-164.

Meldrum, F.C. (2003) Calcium carbonate in biomineralisation and biomimetic chemistry. Int. Mater. Rev. 48:187-224.

Meldrum, F.C., Cölfen, H. (2008) Controlling mineral morphologies and structures in biological and synthetic systems. Chem. Rev. 108:4332-4432.

Merk, V., Chanana, M., Gierlinger, N., Hirt, A.M., Burgert, I. (2014) Hybrid wood materials with magnetic anisotropy dictated by the hierarchical cell structure. ACS Appl. Mater. Interfaces 6:9760-9767.

Merk, V., Chanana, M., Keplinger, T., Gaan, S., Burgert, I. (2015) Hybrid wood materials with improved fire retardance by bioinspired mineralisation on the nano- and submicron level. Green Chem. 17:1423-1428.

Nishimiya, K., Hata, T., Imamura, Y., Ishihara, S. (1998) Analysis of chemical structure of wood charcoal by $\mathrm{X}$-ray photoelectron spectroscopy. J. Wood Sci. 44:56-61.

Petric, M., Murphy, R.J., Morris, I. (2000) Microdistribution of some copper and zinc containing waterborne and organic solvent wood preservatives in spruce wood cell walls. Holzforschung $54: 23-26$. 
Rao, A., Berg, J.K., Kellermeier, M., Gebauer, D. (2014) Sweet on biomineralization: effects of carbohydrates on the early stages of calcium carbonate crystallization. Eur. J. Mineral. [Epub ahead of print].

Rodriguez-Navarro, C., Jimenez-Lopez, C., Rodriguez-Navarro, A., Gonzalez-Munoz, M.T., Rodriguez-Gallego, M. (2007) Bacterially mediated mineralization of vaterite. Geochim. Cosmochim. Acta. 71:1197-1213.

Rutt, H.N., Nicola, J.H. (1974) Raman spectra of carbonates of calcite structure. J. Phys. C: Solid State Phys. 7:4522.

Saka, S., Ueno, T. (1997) Several $\mathrm{SiO}_{2}$ wood-inorganic composites and their fire-resisting properties. Wood Sci. Technol. 31:457-466.

Satterfield, C.N., Feakes, F. (1959) Kinetics of the thermal decomposition of calcium carbonate. AIChE J. 5:115-122.

Schartel, B., Bartholmai, M., Knoll, U. (2005) Some comments on the use of cone calorimeter data. Polym. Degrad. Stab. 88:540-547.

Schartel, B., Hull, T.R. (2007) Development of fire-retarded materials - interpretation of cone calorimeter data. Fire Mater. 31:327-354.

Shafizadeh, F. (1982) Introduction to pyrolysis of biomass. J. Anal. Appl. Pyrolysis. 3:283-305.

Sheng Han, Y., Hadiko, G., Fuji, M., Takahashi, M. (2006) Crystallization and transformation of vaterite at controlled pH. J. Cryst. Growth. 289:269-274.
Simkovic, I., Martonova, H., Manikova, D., Grexa, O. (2005) Flame retardance of insolubilized silica inside of wood material. J. Appl. Polym. Sci. 97:1948-1952.

Simkovic, I., Martvonova, H., Manikova, D., Grexa, O. (2007) Flammability studies of sodium thiosulphate or metabisulphite impregnated wood using cone calorimeter. Fire Mater. 31:137-145.

Sonnier, R., Ferry, L., Longuet, C., Laoutid, F., Friederich, B., Laachachi, A., Lopez-Cuesta, J.M. (2011) Combining cone calorimeter and PCFC to determine the mode of action of flameretardant additives. Polym. Adv. Technol. 22:1091-1099.

Spanos, N., Koutsoukos, P.G. (1998) The transformation of vaterite to calcite: effect of the conditions of the solutions in contact with the mineral phase. J. Cryst. Growth. 191:783-790.

Tampieri, A., Sprio, S., Ruffini, A., Celotti, G., Lesci, I.G., Roveri, N. (2009) From wood to bone: multi-step process to convert wood hierarchical structures into biomimetic hydroxyapatite scaffolds for bone tissue engineering. J. Mater. Chem. 19:4973-4980.

Tsioptsias, C., Panayiotou, C. (2011) Thermal stability and hydrophobicity enhancement of wood through impregnation with aqueous solutions and supercritical carbon dioxide. J. Mater. Sci. 46:5406-5411.

White, R.H. (1987) Effect of lignin content and extractives on the higher heating value of wood. Wood Fiber Sci. 19:446-452.

Xyla, A.G., Koutsoukos, P.G. (1989) Quantitative analysis of calcium carbonate polymorphs by infrared spectroscopy. J. Chem. Soc., Faraday Trans. 1F. 85:3165-3172. 